DOI 10.37882/2223-2982.2021.11.23

\title{
МЕТОДИКА ПОДГОТОВКИ БУДУЩИХ СТУДЕНТОВ-ХОРЕОГРАФОВ К ПЕДАГОГИЧЕСКОЙ ДЕЯТЕЛЬНОСТИ В ШКОЛАХ КАДЕТСКОГО ТИПА
}

\section{METHODOLOGY OF TRAINING OF FUTURE CHOREOGRAPHY TEACHERS IN UNIVERSITIES TO TEACHING IN SCHOOLS OF THE CADET TYPE}

\section{O. Novikova}

Summary: Purpose of the article: describe the particular qualities of the system of work on the preparation of future choreographers in pedagogical activity in schools of the cadet type, to determine the effectiveness of the developed methodology for preparing future choreographers for pedagogical interaction. Research objectives: to conduct a formative experiment; describe the res ults of the comparative analysis before and after the implementation of the author's methodology. The object is the professional training of students-choreographers in a cultural university. Subject: a pedagogical system for preparing future students of choreographers for pedagogical activities in a cadet-type school. Research hypothesis: professional training of teachers-choreographers provides social conditions for the formation of cadets' readiness to master a future profession in the field of civic responsibility and a high level of risk. As a result of the study, the effectiveness of the author's methodology for preparing future students-choreographers for pedagogical activity in cadet-type schools has been determined.

Keywords: methods of work of future students-choreographers, cadet schools, future choreography teachers.

\author{
Новикова Ольга Витальевна \\ Педагог, Белгородский Государственный Институт \\ Искусств и Культуры \\ olsen.energy.nov@mail.ru
}

Аннотация: Цель статьи: раскрыть особенности системы работы по подготовке будущих хореографов в педагогической деятельности в школах кадетского типа, выявить эффективность разработанной методики по подготовке будущих хореографов к педагогическому взаимодействию. Задачи: провести формирующий эксперимент; описать результаты сравнительного анализа до и после реализации авторской методики. Объект исследования - профессиональная подготовка студентов-хореографов в культурном вузе. Предмет исследования - педагогическая система подготовки будущих студентов хореографов к педагогической деятельности в школе кадетского типа. Гипотеза исследования: профессиональная подготовка педагогов-хореографов обеспечивает социальные условия формирования готовности кадетов к освоению будущей профессии в сфере гражданской ответственности и высокого уровня риска.

В результате исследования определена эффективность авторской методики по подготовке будущих студентов-хореографов к педагогической деятельности в школах кадетского типа.

Ключевые слова: методы работы будущих студентов-хореографов, школы кадетского типа, будущие учителя хореографии.

К.Б. Авраменко и А.Н. Сенюк [1] определяют, что для профессиональной подготовки студентов-хореографов к педагогическому взаимодействию важно с одной стороны усвоение базовых понятий и формирования практических навыков в данной сфере, с другой стороны важно осуществлять комплексный подход, где синкретично сочетаются творческая функция обучения и информационная функция.

Л.А. Митакович [2] считает, что при подготовке будущих студентов-хореографов важно реализовывать инновационные походы, разрабатывая методику подготовки студентов, учитывая веяния современной действительности.

Т.В. Осипова [3] в исследовании ценностных ориентаций будущих хореографов определяла важным элементом в процессе их подготовки - это организацию процесса адаптации студентов с окружающей средой, 
учитывая при этом индивидуальные особенности личности студентов-хореографов.

В данной статье мы предлагаем авторскую методику, которая по своей структуре сочетает систему операций, процедур, описания особенностей педагогической деятельности.

Методика направлена на развитие уровней компетентности в сфере подготовки будущих специалистовхореографов к педагогической деятельности, в рамках одной из педагогических дисциплин.

Методика разработана с учетом особенностей компетентности педагогического взаимодействия студентов-хореографов; направлена на развитие подготовки студентов-хореографов к успешному восприятию дисциплины; организацию обучения на основе отдельных модулей дисциплины; организации самостоятельной и внеучебной работы студентов-хореографов; организации совместной деятельности педагога и студентов.

В основе методики располагается три этапа: этап актуализации, дифференциации и интеграции, которые повторяются в процессе изучения каждого модуля дисциплины.

Структура методики включает пять модулей, в каждом из которых разработана своя технологическая карта, которая позволяет оценить уровень освоения педагогического взаимодействия у студентов.

Первый модуль «Ценности, цели и смыслы педагогической работы с подростками-кадетами» включает несколько важных целей. К ним относится формирование у студентов отношения к своей системе взглядов и направления развития; формирование способности к пониманию и оценке мировоззрения.

Таким образом, основной упор при реализации данного модуля реализуется с учетом мировоззренческих знаний личности.

Во втором модуле, направленном на определение социально-педагогического познания студентов-хореографов, изучаются представления студентов о педагогической и познавательной сферах.

Следующей важной целью является развитие способности понимать и решать педагогико-интеллектуальные и эмоционально-интеллектуальные задачи в педагогической сфере.

Третий модуль представляет собой изучение структуры педагогической деятельности студентов-хореографов в воспитательной работе, здесь основной целью является изучение представлений студентов в сфере самоорганизации личности и отношении к совместной деятельности.

Четвертый модуль включает анализ результатов по воспитательной работе на уровне рефлексии. Он имеет основную цель, которая конкретизирована в формировании осознанного представления о субъективном рефлексивном опыте педагогического взаимодействия.

Авторская методика способствует достижению результатов в двух направлениях на предметном уровне и метапредметном.

Цель: выявить эффективность разработанной методики по подготовке будущих хореографов к педагогическому взаимодействию.

\section{Задачи исследования:}

1. провести формирующий эксперимент;

2. описать результаты сравнительного анализа до и после реализации авторской методики.

Объект: профессиональная подготовка студентов-хореографов в культурном вузе.

Предмет: педагогическая система подготовки будущих студентов хореографов к педагогической деятельности в школе кадетского типа.

Гипотеза исследования: профессиональная подготовка педагогов-хореографов обеспечивает социальные условия формирования готовности кадетов к освоению будущей профессии в сфере гражданской ответственности и высокого уровня риска.

База исследования: Белгородский государственный университет. В исследовании задействованы 2 курса факультета хореографии, контрольную группу составили 2 учебных курса в количестве 82 респондентов.

В результате реализации авторской методики было определено, что в экспериментальной группе существенно улучшились показатели высокого творческого уровня компетентности педагогического взаимодействия студентов с 21,4\% до 47,6\%.; средний уровень улучшился с $33,3 \%$ до 45,2\%; низкий уровень изменился и понизился с 45,2\% до 7,2\% от общего числа респондентов.

В контрольной группе показатели уровней компетентности педагогического взаимодействия студентов не претерпели существенных изменений: высокий уровень изменился всего на $5 \%$, с 22,5\% на 27,5\% от общего числа респондентов; средний уровень увеличился на $10 \%$ и изменился с $30 \%$ до 40\%; низкий уровень изме- 
нился на $12,5 \%$ - от 47,5\% до $35 \%$.

С целью определения эффективности разработанной авторской методике по формированию высоких показателей компетентности педагогического взаимодействия студентов-хореографов сравнивалась динамика изменений формируемых компетенций в обеих группах, и определялось ее средневзвешенное значение, опираясь на процедуру шкалирования.

Мы исходили их того, что низкий - то есть не продуктивный уровень компетентности соответствует 1 баллы по условной трехбалльной шкале, тогда как нормативно-продуктивный или средний уровень 2 баллам, творческий или высокий уровень компетентности педагогического взаимодействия студентов-хореографов со- ответствует по условной шкале 3 баллам.

В результате абсолютный прирост составляет среди респондентов экспериментальной группы хЭ =0,640 и $\mathrm{xK}=0,220$ у респондентов контрольной группы. Их отношение составляет 2,9. Сравнительные результаты составили увеличение в 2,91 раз.

Таким образом, наблюдается существенное улучшение показателей уровней компетентности педагогического взаимодействия у студентов в экспериментальной группе, что наглядно демонстрирует и доказывает эффективность разработанной авторской методики по подготовке будущих студентов - хореографов к педагогической деятельности в школах кадетского типа.

\section{ЛИТЕРАТУРА}

1. Авраменко К.Б., Сенюк А.Н. Профессиональная подготовка будущих учителей хореографии в системе педагогического образования // Успехи современного естествознания. - 2011. - № 8. - С. 149-150

2. Митакович Л.А. Подготовка будущих педагогов-хореографов к решению профессиональных задач // Известия РГПУ им. А.И. Герцена. 2009. №116. - С. 185 - 188

3. Осипова М.К. Профессиональная подготовка будущих артистов балета к исполнению прыжковых движений: Учебное пособие / М.К. Осипова, СПб. : Лань; Планета музыки, 2019. - 196 с.

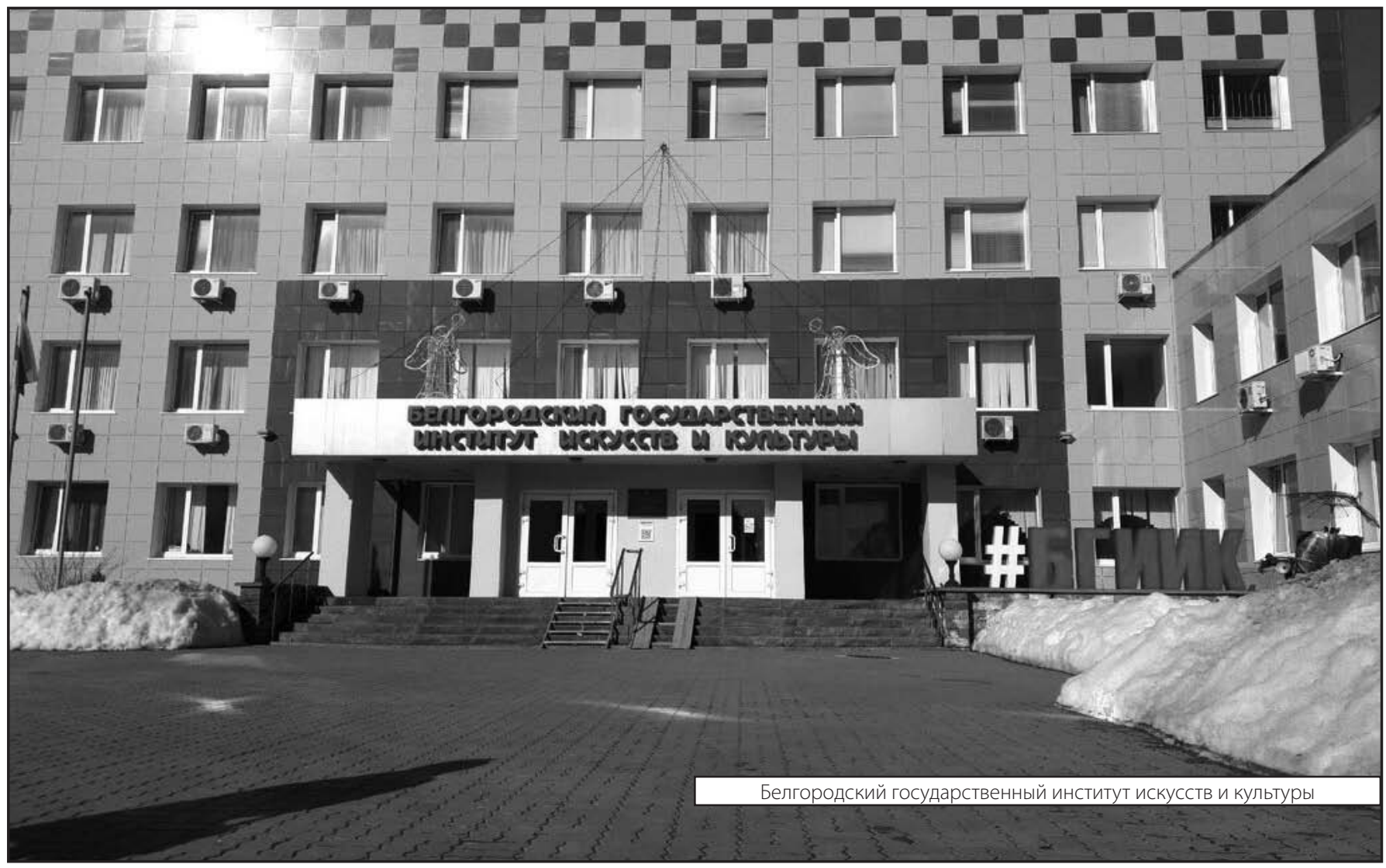

